\title{
A Drug-Drug Interaction Study to Investigate the Effect of Nintedanib on the Pharmacokinetics of Microgynon (Ethinylestradiol and Levonorgestrel) in Female Patients with Systemic Sclerosis-Associated Interstitial Lung Disease
}

\author{
Madelon C. Vonk ${ }^{1}$ (1) - Alfredo Guillén-Del-Castillo ${ }^{2} \cdot$ Michael Kreuter $^{3} \cdot$ Mandy Avis $^{4} \cdot$ Kristell Marzin $^{5}$. \\ Salome R. Mack ${ }^{5}$ Sven Wind ${ }^{5} \cdot$ Martina Gahlemann $^{6}$
}

Accepted: 28 September 2021 / Published online: 18 October 2021

(c) The Author(s) 2021

\begin{abstract}
Background and Objectives Nintedanib is a tyrosine kinase inhibitor approved for the treatment of systemic sclerosis-associated interstitial lung disease (SSc-ILD), idiopathic pulmonary fibrosis, and other chronic fibrosing ILDs with a progressive phenotype. As nintedanib may cause foetal harm, patients taking nintedanib should avoid pregnancy. The objective of this study was to investigate the effect of nintedanib co-administration on the pharmacokinetics of Microgynon (ethinylestradiol and levonorgestrel) in female patients with SSc-ILD.

Methods This was an open-label, two-period, fixed-sequence, drug-drug interaction study. Female patients with SSc and $\geq 10 \%$ extent of fibrotic ILD on a high-resolution computed tomography scan were eligible to participate. In Period 1, patients received one Microgynon tablet (ethinylestradiol $30 \mu \mathrm{g}$ and levonorgestrel $150 \mu \mathrm{g}$ ) $\geq 3$ days before the first administration of nintedanib in Period 2. In Period 2, patients received one Microgynon tablet following intake of nintedanib $150 \mathrm{mg}$ twice daily for $\geq 10$ consecutive days. The primary pharmacokinetic endpoints were the areas under the plasma concentration-time curve of ethinylestradiol and levonorgestrel over the time interval from 0 to the last quantifiable data point $\left(\mathrm{AUC}_{0-\mathrm{tz}}\right)$ and the maximum measured concentrations of ethinylestradiol and levonorgestrel in plasma $\left(C_{\max }\right)$. The secondary pharmacokinetic endpoint was the area under the plasma concentration-time curve of ethinylestradiol and levonorgestrel over the time interval from 0 extrapolated to infinity $\left(\mathrm{AUC}_{0-\infty}\right)$. The relative exposures of ethinylestradiol and levonorgestrel when administered alone and in combination with nintedanib were assessed using an ANOVA model.

Results Seventeen patients were treated. Pharmacokinetic data from 15 patients were analysed. Plasma concentration-time profiles of ethinylestradiol and levonorgestrel were similar following administration of Microgynon before and after administration of nintedanib for $\geq 10$ consecutive days. Adjusted geometric mean (gMean) ratios [90\% confidence intervals (CIs)] for $\mathrm{AUC}_{0-\mathrm{tz}}(101.4 \%[92.8,110.7])$ and $\mathrm{AUC}_{0-\infty}(101.2 \%[94.0,109.1])$ indicated that there was no difference in total ethinylestradiol exposure when Microgynon was administered before or after administration of nintedanib. The adjusted gMean ratio for $C_{\max }$ of ethinylestradiol $(116.7 \%$ [90\% CI 107.6, 126.5]) indicated an increase in peak exposure in the presence of nintedanib. Adjusted gMean ratios $[90 \% \mathrm{CIs}]$ for $\mathrm{AUC}_{0-\mathrm{tz}}(96.4 \%[91.5,101.6])$ and $C_{\max }(100.9 \%[89.9,113.2])$ indicated that there was no difference in total or peak levonorgestrel exposure when Microgynon was administered before or after administration of nintedanib. The adjusted gMean ratio for $\mathrm{AUC}_{0-\infty}$ of levonorgestrel indicated a decrease in total exposure in the presence of nintedanib (88.1\% [90\% CI 80.0, 97.0]).
\end{abstract}

Conclusion Pharmacokinetic data indicate that there is no relevant effect of nintedanib on plasma exposure to ethinylestradiol and levonorgestrel in female patients with SSc-ILD.

Trial Registration Clinicaltrials.gov NCT03675581.

Extended author information available on the last page of the article 


\section{Key Points}

Pharmacokinetic data indicate that there is no relevant effect of nintedanib on plasma exposure to Microgynon (ethinylestradiol and levonorgestrel) in female patients with systemic sclerosis-associated interstitial lung disease.

Thus, nintedanib is not expected to reduce the effectiveness of contraceptives containing ethinylestradiol and levonorgestrel due to drug-drug interaction.

\section{Introduction}

Nintedanib is an approved treatment for idiopathic pulmonary fibrosis (IPF), other chronic fibrosing interstitial lung diseases (ILDs) with a progressive phenotype, and systemic sclerosis-associated ILD (SSc-ILD). Nintedanib is an intracellular inhibitor of tyrosine kinases, including the platelet-derived growth factor receptor, fibroblast growth factor receptor, and vascular endothelial growth factor receptor [1, 2]. Non-clinical studies suggest that nintedanib inhibits processes fundamental to the progression of pulmonary fibrosis, including fibroblast activation and the deposition of extracellular matrix [2]. Clinical trials have demonstrated that over 52 weeks, treatment with nintedanib slows the rate of decline in forced vital capacity (FVC) (mL/year) by approximately $50 \%$ compared with placebo, with side-effects that are predominantly gastrointestinal in nature [3-5].

Nintedanib is administered orally at a dose of $150 \mathrm{mg}$ twice daily (bid), with dose reductions to $100 \mathrm{mg}$ bid and treatment interruptions recommended to manage adverse events [6]. Maximum plasma concentrations of nintedanib are reached approximately $2-4 \mathrm{~h}$ after oral administration, and steady state is reached within 7 days [7]. Nintedanib is metabolised via hydrolytic ester cleavage, resulting in the formation of the free acid moiety, which is glucuronidated and excreted in faeces via the liver [8].

Some patients prescribed nintedanib are of child-bearing age. This includes some patients with SSc-ILD, which occurs mainly in women [9]. As nintedanib may cause foetal harm, patients taking nintedanib should avoid pregnancy [6]. The European Medicines Agency (EMA) and US Food and Drug Administration (FDA) recommend that the potential for pharmacokinetic interactions between nintedanib and oral contraceptives should be evaluated. We therefore conducted a drug-drug interaction study to investigate the potential effects of nintedanib on the pharmacokinetics of
Microgynon ${ }^{\circledR}$, a commonly used oral contraceptive including ethinylestradiol (a synthetic oestrogen) and levonorgestrel (a progestogen derived from nortestosterone), in female patients with SSc-ILD.

\section{Methods}

\subsection{Study Patients}

Female patients aged $\geq 18$ years with SSc (based on the American College of Rheumatology/European League Against Rheumatism classification criteria [9]) and $\geq 10 \%$ extent of fibrotic ILD on a high-resolution computed tomography (HRCT) scan were eligible to participate. Patients were required to be of non-childbearing potential or, following a protocol amendment, of childbearing potential and using a highly effective method of non-hormonal birth control together with barrier methods. Patients with aspartate transaminase, alanine transaminase and/or bilirubin $>1.5$ times the upper limit of normal; clinically relevant anaemia; pre-bronchodilator forced expiratory volume in $1 \mathrm{~s} / \mathrm{FVC}<$ 0.7; significant pulmonary hypertension (previous clinical or echocardiographic evidence of significant right heart failure, history of right heart catheterisation with a cardiac index $\leq$ $2 \mathrm{~L} / \mathrm{min} / \mathrm{m}^{2}$, or pulmonary hypertension requiring therapy with parenteral or oral prostacyclins); or at risk of bleeding (e.g., those with a known predisposition to bleeding or those who were taking high-dose antiplatelet therapy or full-dose anticoagulation) were excluded.

\subsection{Study Design}

This was an open-label, multicentre, two-period, fixedsequence, drug-drug interaction study to investigate the relative systemic exposure to ethinylestradiol and levonorgestrel alone and in combination with steady-state nintedanib (clinicaltrials.gov NCT03675581; EudraCT 2018-001177-24).

Patients participated in two periods in a fixed sequence (Fig. 1). In Period 1, patients received one Microgynon tablet (Bayer; ethinylestradiol $30 \mu \mathrm{g}$ and levonorgestrel $150 \mu \mathrm{g}$ ) $\geq 3$ days before the first administration of nintedanib (Ofev ${ }^{\circledR}$; Boehringer Ingelheim Pharma $\mathrm{GmbH} \& \mathrm{Co}$. KG, Ingelheim, Germany) in Period 2. In Period 2, patients received one Microgynon tablet following intake of nintedanib 150 $\mathrm{mg}$ bid for $\geq 10$ consecutive days. Patients could receive nintedanib $150 \mathrm{mg}$ bid for a total of 14-28 days to ensure continuous treatment to steady state. Nintedanib dose reduction to $100 \mathrm{mg}$ bid or treatment interruption was permitted to manage adverse events. The maximum period of treatment interruption was 4 weeks for adverse events considered related to the trial drug and 8 weeks for adverse events 

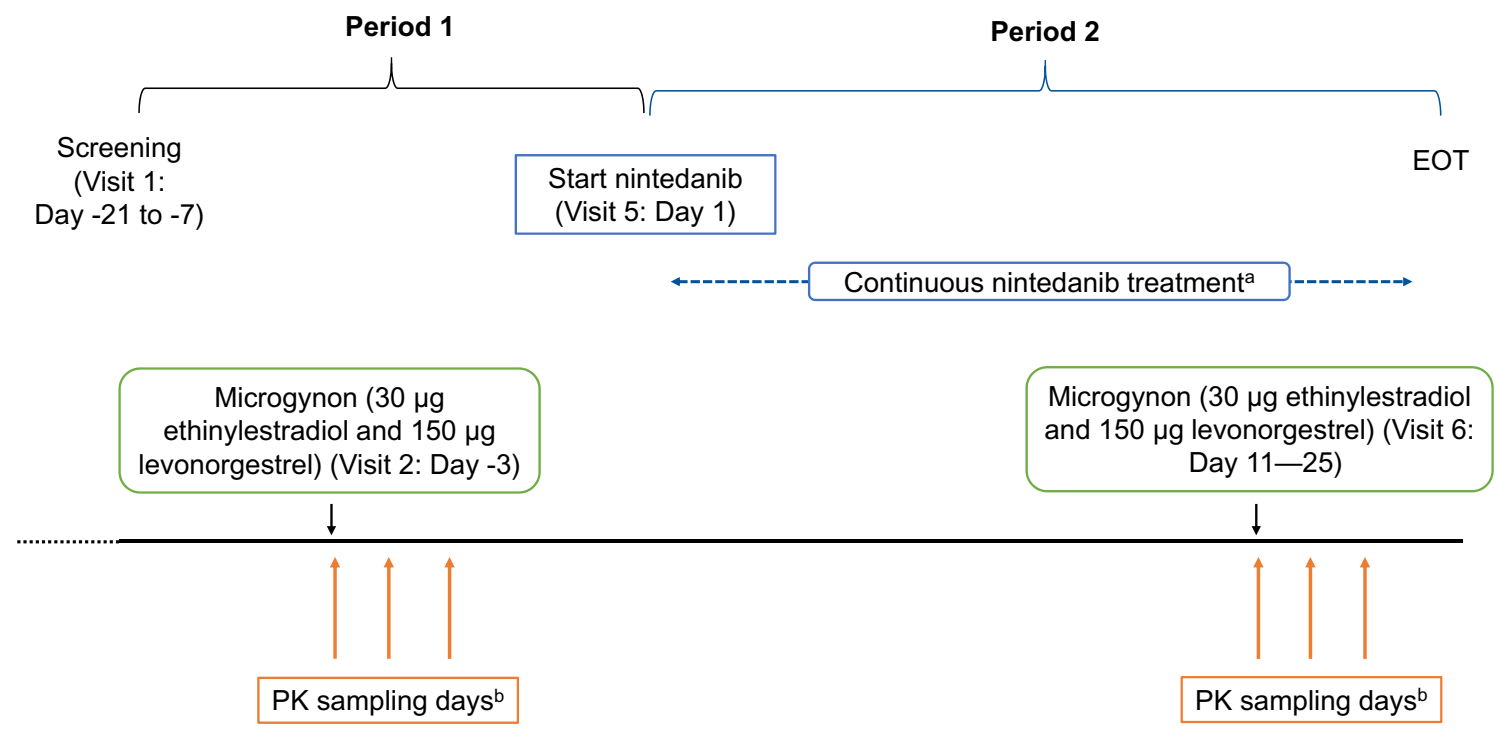

Fig. 1 Study design. ${ }^{\text {aPatients }}$ received nintedanib $150 \mathrm{mg}$ bid for $\geq 10$ consecutive days prior to Microgynon administration in Period 2. Patients received nintedanib $150 \mathrm{mg}$ bid over a period of $\geq 14$ days to approximately 28 days. ${ }^{b}$ Blood samples for PK evaluation were

considered not drug related. Blood samples for pharmacokinetic evaluation were collected on the days of Microgynon administration (pre- and post-dose) and on the following 2 days in both periods. Specifically, pharmacokinetic sampling for ethinylestradiol and levonorgestrel was performed $35 \mathrm{~min}$ before and $30 \mathrm{~min}, 1 \mathrm{~h}, 1 \mathrm{~h} 30 \mathrm{~min}, 2 \mathrm{~h}, 3 \mathrm{~h}, 4 \mathrm{~h}, 6 \mathrm{~h}, 8 \mathrm{~h}, 11$ h $55 \mathrm{~min}, 23 \mathrm{~h} 55 \mathrm{~min}$, and $47 \mathrm{~h} 55 \mathrm{~min}$ after Microgynon administration in Periods 1 and 2. Pharmacokinetic sampling for nintedanib was performed $35 \mathrm{~min}$ before and $23 \mathrm{~h} 55 \mathrm{~min}$ and $47 \mathrm{~h} 55 \mathrm{~min}$ after Microgynon administration in Period 2. In Periods 1 and 2, $6 \mathrm{~mL}$ of blood was drawn at each time point to prepare the samples for the pharmacokinetic analysis of ethinylestradiol and levonorgestrel. In Period 2, $3 \mathrm{~mL}$ of blood was drawn at each of the three time points to prepare the samples for the pharmacokinetic analysis of nintedanib. Blood was collected using tripotassium ethylenediaminetetraacetic acid (K3-EDTA)-containing blood drawing tubes. The tubes were gently inverted ten times and then centrifuged at $2100 \mathrm{~g}$ for $15 \mathrm{~min}$ at $4-25{ }^{\circ} \mathrm{C}$ within 60 min of sampling. At least $1.5 \mathrm{~mL}$ of plasma was transferred into two cryovials within $30 \mathrm{~min}$ of centrifugation (aliquot 1 and back-up aliquot 2) and stored in an upright position at $-20{ }^{\circ} \mathrm{C}$ or below until shipment to the central laboratory (Nuvisan $\mathrm{GmbH}$ ) for analysis.

Patients were to be excluded if they had received P-glycoprotein (P-gp) and cytochrome P450 3A4 (CYP3A4) inhibitors or inducers within 7 days prior to the first dose of Microgynon. Use of these medications was not permitted until the last pharmacokinetic sampling day. Patients were to be excluded if they had received mycophenolate (within collected on the days of Microgynon administration (pre- and postdose) and on the following 2 days. EOT end of treatment, $P K$ pharmacokinetic, bid twice daily

2 weeks prior to the first dose of Microgynon), azathioprine (within 8 weeks prior to screening), cyclophosphamide (within 6 months prior to screening) or cyclosporine (within 7 days prior to the first dose of Microgynon). Use of methotrexate was permitted if the dose had been stable for $\geq 6$ months prior to screening. Patients were to be excluded if they had received hormone-containing contraceptives $<30$ days prior to the first dose of Microgynon. Use of hormonecontaining contraceptives was not permitted at any time during the study.

The study was carried out in compliance with the protocol and in accordance with the principles of the Declaration of Helsinki, the International Council for Harmonisation good clinical practice guideline, and applicable regulatory requirements. All patients provided written informed consent.

\subsection{Endpoints}

The primary pharmacokinetic endpoints were the area under the plasma concentration-time curve of ethinylestradiol and levonorgestrel over the time interval from 0 to the last quantifiable data point $\left(\mathrm{AUC}_{0-\mathrm{tz}}\right)$ and the maximum measured concentrations of ethinylestradiol and levonorgestrel in plasma $\left(C_{\max }\right)$. The secondary pharmacokinetic endpoint was the area under the plasma concentration-time curve of ethinylestradiol and levonorgestrel over the time interval from 0 extrapolated to infinity $\left(\mathrm{AUC}_{0-\infty}\right)$. Further pharmacokinetic endpoints were the pre-dose (trough) plasma concentration of nintedanib at steady state $\left(C_{\text {pre,ss }}\right)$ and clearance 
$(\mathrm{CL} / F)$, volume of distribution $\left(V_{\mathrm{z}} / F\right)$, time to reach $C_{\max }$ $\left(t_{\max }\right)$, terminal rate constant $\left(\lambda_{\mathrm{z}}\right)$, terminal elimination halflife $\left(t_{1 / 2}\right)$, and time point of the last quantifiable plasma concentration $\left(t_{\mathrm{z}}\right)$ of ethinylestradiol and levonorgestrel. Nintedanib $C_{\text {pre,ss }}$ was assessed to prove exposure on the day of Microgynon administration and on the following 2 days during continuous nintedanib intake.

Safety was assessed based on adverse events, laboratory tests, vital signs, spirometry, physical examination, 12-lead electrocardiogram and echocardiography. Adverse events were reported irrespective of causality and coded using the Medical Dictionary for Regulatory Activities version 22.1. The following phases were defined for the recording of adverse events: adverse events reported from (1) the date of administration of Microgynon in Period 1 plus 3 days, (2) the first administration of nintedanib in Period 2 until the date of administration of Microgynon in Period 2, (3) the date of administration of Microgynon in Period 2 plus 3 days, and (4) the date 3 days after the administration of Microgynon in Period 2 until the day after last contact.

\subsection{Bioanalytical Assay}

Plasma concentrations of nintedanib, ethinylestradiol and levonorgestrel were determined using a liquid chromatography tandem mass spectrometry assay (LC-MS/MS). The assay method for nintedanib (in the form of its free base, BIBF 1120 BS) involved solid-phase extraction, chromatographic separation on a Phenomenex Luna (C18) column under gradient conditions, and MS/MS detection (MRM-mode) using [2H8]-BIBF $1120 \mathrm{BS}$ as an internal standard. An electrospray ion source (atmospheric pressure ionisation [API]) was used for ionisation. Measurements were performed in the positive ionisation mode. The LC-MS/MS method was validated at Nuvisan GmbH in accordance with internationally accepted standards. The calibration range was $0.05-50 \mathrm{ng} / \mathrm{mL}$ and recovery was in the range of 70.1-71.6\%. The assay method for ethinylestradiol and levonorgestrel involved liquid-liquid extraction and derivatisation, chromatographic separation on a Waters XBridge BEH18 column under gradient conditions, and MS/MS detection using [2H4]-ethinylestradiol and [2H6]-levonorgestrel as internal standards. An electrospray ion source (API) was used for ionisation. Measurements were performed in the positive ionisation mode. The LC-MS/MS method was validated at Nuvisan $\mathrm{GmbH}$ in accordance with internationally accepted standards. The calibration range was $2.5-250 \mathrm{pg} / \mathrm{mL}$ for ethinylestradiol and $25-25000 \mathrm{pg} / \mathrm{mL}$ for levonorgestrel. Recovery was in the range of $95.4-129.3 \%$ for ethinylestradiol and $91.5-112.2 \%$ for levonorgestrel. For both assays, performance was assessed by back-calculation of calibration standards, tabulation of the standard curve fit function parameters and measurement of quality control samples. No data were extrapolated. Samples below the lower limit of quantification (LLOQ) were reported as < LLOQ. There were no samples above the upper limit of quantification.

\subsection{Analyses}

Pharmacokinetic analyses were performed in patients who received $\geq 1$ dose of Microgynon or nintedanib and provided $\geq 1$ value for $\geq 1$ primary or secondary endpoint without important protocol violations or non-evaluability relevant to the evaluation of pharmacokinetics. Safety analyses were performed in patients who received $\geq 1$ dose of Microgynon or nintedanib.

The relative systemic exposures of ethinylestradiol and levonorgestrel alone (reference [R]) and in combination with steady-state nintedanib (test [T]) were assessed using an ANOVA model on a logarithmic scale with patient included as a random effect and treatment included as a fixed effect. Values for $\mathrm{AUC}_{0-\mathrm{tz}}, C_{\max }$ and $\mathrm{AUC}_{0-\infty}$ were log-transformed prior to fitting the model. The difference between the expected means for $\log (T)-\log (R)$ was estimated using the difference in the corresponding least-squares means, and two-sided $90 \%$ confidence intervals (CIs) were computed based on the $t$ distribution. Values were back-transformed to the original scale to give the geometric mean (gMean) and two-sided 90\% CIs for the ratio between response under $T$ versus $R$ treatment. Further pharmacokinetic endpoints and safety were analysed descriptively.

The observed intra-individual coefficient of variation $(\mathrm{gCV})$ values for ethinylestradiol and levonorgestrel in healthy volunteers have been estimated to be approximately $20 \%$ for $C_{\max }$ and $15 \%$ for $\mathrm{AUC}_{0-\mathrm{tz}}$ or $\mathrm{AUC}_{\tau, \mathrm{ss}}$. Based on a sample size of 14 patients and assuming a $\mathrm{gCV}$ of $20 \%$, the precision of the two-sided $90 \%$ CI of the $T: R$ ratio in terms of the upper confidence limit/point estimate would have been approximately 1.19. Thus, a sample size of 14 patients was considered sufficient to achieve the aims of this exploratory study.

Pharmacokinetic parameter calculations were performed using Phoenix ${ }^{\circledR}$ WinNonlin ${ }^{\circledR} 6.3$ (or later) and/or SAS ${ }^{\circledR}$ software, version 9.4 (or later). For $\mathrm{AUC}_{0-\infty}$ calculations, the linear up-log down trapezoidal rule was applied (the linear trapezoidal rule was used for the ascending parts of the concentration-time profiles, and the logarithmic trapezoidal rule was used for the descending parts of the concentration-time profiles).

\section{Results}

\subsection{Patients}

A total of 21 patients were screened: 17 were treated and four failed screening. Mean (SD) age was 59.1 (13.2) years and body mass index was $27.1(4.7) \mathrm{kg} /$ $\mathrm{m}^{2} ; 88.2 \%$ of patients were white (Table 1$)$. Median 
(minimum-maximum) nintedanib exposure was 15 (13-47) days. One patient had a nintedanib dose reduction. All patients completed the study. Data from two patients were not included in the pharmacokinetic analyses due to protocol violations, i.e., the use of restricted medication.

Table 1 Baseline demographic characteristics of study patients $(n=$ 17)

\begin{tabular}{lc}
\hline Characteristic & Value \\
\hline Age, years, mean (SD) & $59.1(13.2)$ \\
Body mass index, $\mathrm{kg} / \mathrm{m}^{2}$, mean (SD) & $27.1(4.7)$ \\
Race, $n(\%)$ & $15(88.2)$ \\
White & $1(5.9)$ \\
Asian & $1(5.9)$ \\
Native Hawaiian or other Pacific Islander & $6.1(4.5)$ \\
Time since onset of non-Raynaud symptom, & \\
years, mean (SD) & $14(82.4)$ \\
Systemic sclerosis subtype, $n$ (\%) & $3(17.6)$ \\
Limited cutaneous & $80.9(19.5)$ \\
Diffuse cutaneous & \\
Forced vital capacity \% predicted, mean (SD)
\end{tabular}

\subsection{Pharmacokinetics}

Ethinylestradiol and levonorgestrel were rapidly absorbed after administration of a single dose of Microgynon. Plasma concentrations of ethinylestradiol and levonorgestrel declined in a bi-exponential manner. Plasma concentration-time profiles of ethinylestradiol and levonorgestrel were similar following administration of Microgynon before and after administration of nintedanib $150 \mathrm{mg}$ bid for $\geq 10$ consecutive days (Figs. 2, 3). $\mathrm{AUC}_{0-\mathrm{tz}}, C_{\max }$ and $\mathrm{AUC}_{0-\infty}$ of ethinylestradiol and levonorgestrel were similar before and after administration of nintedanib $150 \mathrm{mg}$ bid for $\geq 10$ consecutive days (Table 2). Adjusted gMean ratios (90\% CIs) for $\mathrm{AUC}_{0-\mathrm{tz}}$ and $\mathrm{AUC}_{0-\infty}$ indicated that there was no difference in total ethinylestradiol exposure when Microgynon was administered before or after administration of nintedanib for $\geq 10$ consecutive days. The adjusted gMean ratio $(90 \%$ CI) for $C_{\max }$ of ethinylestradiol indicated an increase in peak exposure in the presence of nintedanib (Table 3 ). Adjusted gMean ratios (90\% CIs) for $\mathrm{AUC}_{0-\mathrm{tz}}$ and $C_{\max }$ indicated that there was no difference in levonorgestrel total or peak exposure when Microgynon was administered before or after administration of nintedanib for $\geq 10$ consecutive days. The adjusted gMean ratio $(90 \%$ $\mathrm{CI})$ for $\mathrm{AUC}_{0-\infty}$ of levonorgestrel indicated a decrease in total exposure in the presence of nintedanib (Table 3).

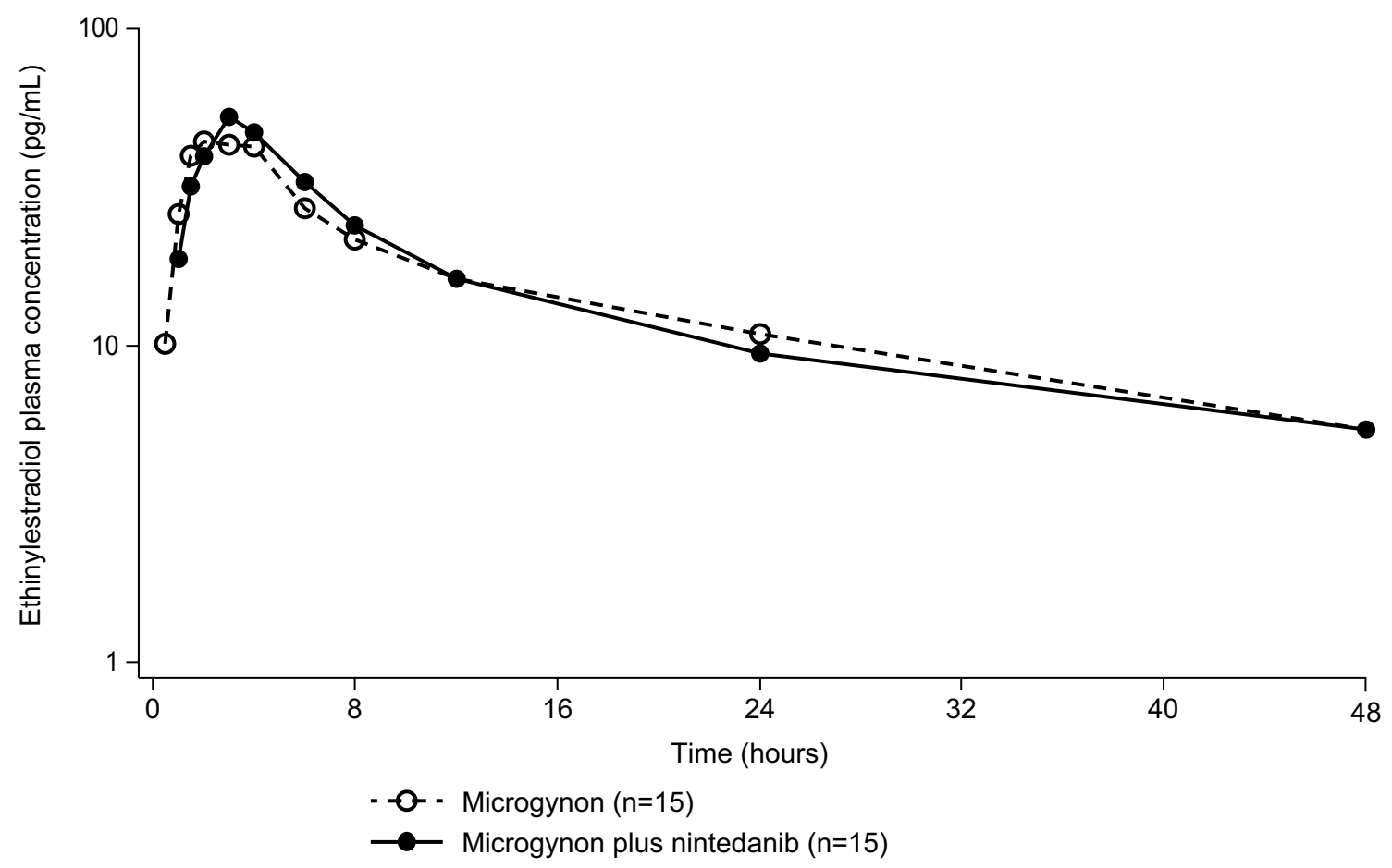

Fig. 2 Geometric mean plasma concentration-time profiles of ethinylestradiol after single-dose administration of Microgynon before (Period 1) and after administration of nintedanib $150 \mathrm{mg}$ bid for $\geq 10$ consecutive days (Period 2), plotted on a semi-logarithmic scale 


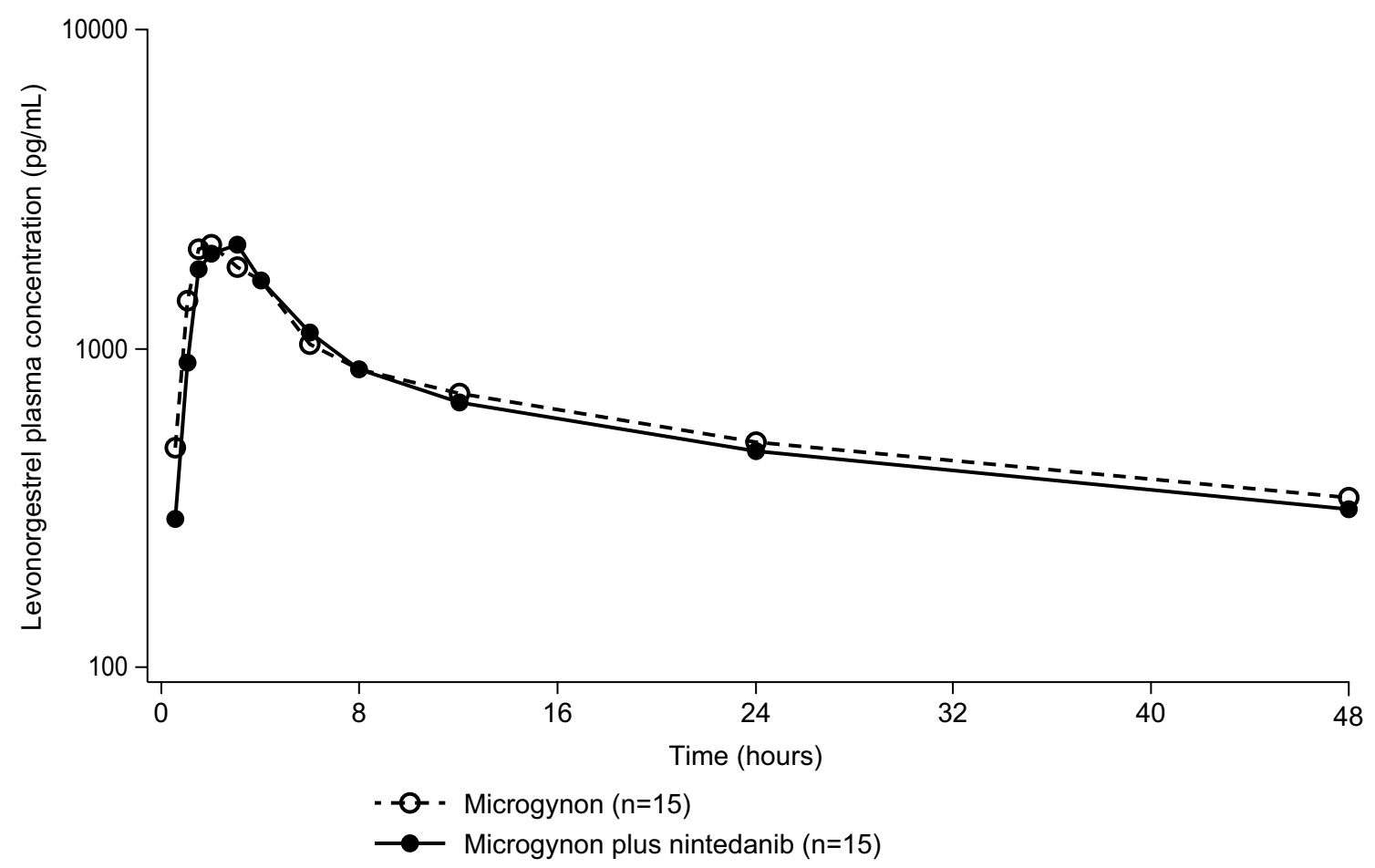

Fig. 3 Geometric mean plasma concentration-time profiles of levonorgestrel after single-dose administration of Microgynon before (Period 1) and after administration of nintedanib $150 \mathrm{mg}$ bid for $\geq 10$ consecutive days (Period 2), plotted on a semi-logarithmic scale

Table 2 Pharmacokinetics of ethinylestradiol and levonorgestrel after single dose administration of Microgynon before and after administration of nintedanib $150 \mathrm{mg}$ bid for $\geq 10$ consecutive days

\begin{tabular}{|c|c|c|c|c|}
\hline \multirow[t]{2}{*}{ Parameter } & \multicolumn{2}{|l|}{ Ethinylestradiol } & \multicolumn{2}{|l|}{ Levonorgestrel } \\
\hline & Microgynon alone $(n=15)$ & $\begin{array}{l}\text { Microgynon with nint- } \\
\text { edanib }(n=15)\end{array}$ & Microgynon alone $(n=15)$ & $\begin{array}{l}\text { Microgynon with } \\
\text { nintedanib }(n=15)\end{array}$ \\
\hline $\mathrm{AUC}_{0-\mathrm{tz}}, \mathrm{pg} \cdot \mathrm{h} / \mathrm{mL}$ & $610(65.6)$ & $618(57.3)$ & $33,100(81.8)$ & $31,900(81.1)$ \\
\hline$C_{\max }, \mathrm{pg} / \mathrm{mL}$ & $54.7(35.6)$ & $63.9(44.7)$ & $3120(55.6)$ & $3150(54.6)$ \\
\hline $\mathrm{AUC}_{0-\infty}, \mathrm{pg} \cdot \mathrm{h} / \mathrm{mL}$ & $750(60.2)$ & $759(51.5)$ & $56,300(102)$ & $49,600(97.2)$ \\
\hline $\mathrm{AUC}_{0-24}, \mathrm{pg} \cdot \mathrm{h} / \mathrm{mL}$ & $490(46.8)$ & $517(43.7)$ & $22,800(76.8)$ & $22,200(75.5)$ \\
\hline $\mathrm{AUC}_{\mathrm{tz}-\infty}, \%$ & $17.8(29.5)$ & $17.2(38.0)$ & $33.9(56.6)$ & $31.6(43.8)$ \\
\hline$t_{\mathrm{z}}, \mathrm{h}$ & $47.9(11.9-48.0)$ & $47.9(23.8-48.3)$ & $47.9(47.9-48.0)$ & $47.9(47.7-48.3)$ \\
\hline$t_{\max }, \mathrm{h}$ & $2.0(1.0-6.0)$ & $3.0(1.0-5.0)$ & $1.6(1.0-4.0)$ & $2.0(1.0-4.0)$ \\
\hline$t_{1 / 2}, \mathrm{~h}$ & $17.4(29.5)$ & $16.7(27.1)$ & $39.4(64.2)$ & $35.0(42.7)$ \\
\hline
\end{tabular}

Data are gMean $(\% \mathrm{gCV})$ except for $t_{\mathrm{z}}$ and $t_{\max }$, which are median (range)

$A U C_{0-t z}$ area under the plasma concentration-time curve of ethinylestradiol or levonorgestrel over the time interval from 0 to the last quantifiable data point, $C_{\max }$ maximum measured concentration of ethinylestradiol or levonorgestrel in plasma, $\mathrm{AUC}_{0-\infty}$ area under the plasma concentration-time curve of ethinylestradiol or levonorgestrel over the time interval from 0 extrapolated to infinity, $A U C_{0-24}$ area under the plasma concentration-time curve of ethinylestradiol or levonorgestrel over the time interval from 0 to $24 \mathrm{~h}, A U C_{t z-\infty} \mathrm{AUC}_{0-\infty}$ obtained by extrapolation, $t_{z}$ time point of the last quantifiable plasma concentration, $t_{\max }$ time from (last) dosing to the maximum measured plasma concentration of ethinylestradiol or levonorgestrel, $t_{1 / 2}$ terminal half-life of ethinylestradiol or levonorgestrel in plasma, $g$ Mean geometric mean, $g C V$ geometric coefficient of variation

Eleven patients in Period 1 and 10 patients in Period 2 had extrapolated areas of $>30 \%$ due to pharmacokinetic sampling limited to $48 \mathrm{~h}$.

\subsection{Safety}

The most frequently reported adverse events were nausea $(35.3 \%)$, diarrhoea $(29.4 \%)$ and vomiting $(29.4 \%)$ (Table 4). One patient had a serious adverse event 
Table 3 Relative exposure to ethinylestradiol and levonorgestrel after single dose administration of Microgynon before and after administration of nintedanib $150 \mathrm{mg}$ bid for $\geq 10$ consecutive days

\begin{tabular}{|c|c|c|c|}
\hline \multirow[t]{2}{*}{ Parameter } & \multicolumn{2}{|l|}{ Adjusted $^{\mathrm{a}}$ gMean $(\mathrm{gSE})$} & \multirow{2}{*}{$\begin{array}{l}\text { Adjusted gMean ratio, } \\
\%(90 \% \mathrm{CI})[T] /[R]\end{array}$} \\
\hline & $\begin{array}{l}\text { Microgynon with nintedanib } \\
(n=15)[T]\end{array}$ & $\begin{array}{l}\text { Microgynon alone }(n= \\
\text { 15) }[R]\end{array}$ & \\
\hline \multicolumn{4}{|l|}{ Ethinylestradiol } \\
\hline $\mathrm{AUC}_{0-\mathrm{tz}}, \mathrm{pg} \cdot \mathrm{h} / \mathrm{mL}$ & $618.3(1.2)$ & $610.0(1.2)$ & $101.4(92.8,110.7)$ \\
\hline$C_{\max }, \mathrm{pg} / \mathrm{mL}$ & $63.9(1.1)$ & $54.8(1.1)$ & $116.7(107.6,126.5)$ \\
\hline $\mathrm{AUC}_{0-\infty}, \mathrm{pg} \cdot \mathrm{h} / \mathrm{mL}$ & $759.0(1.1)$ & $749.7(1.1)$ & $101.2(94.0,109.1)$ \\
\hline \multicolumn{4}{|l|}{ Levonorgestrel } \\
\hline $\mathrm{AUC}_{0-\mathrm{tz}}, \mathrm{pg} \cdot \mathrm{h} / \mathrm{mL}$ & $31872.5(1.2)$ & 33062.7 (1.2) & $96.4(91.5,101.6)$ \\
\hline$C_{\max }, \mathrm{pg} / \mathrm{mL}$ & $3152.4(1.1)$ & $3124.5(1.1)$ & $100.9(89.9,113.2)$ \\
\hline $\mathrm{AUC}_{0-\infty}, \mathrm{pg} \cdot \mathrm{h} / \mathrm{mL}$ & $49605.4(1.2)$ & $56311.7(1.2)$ & $88.1(80.0,97.0)$ \\
\hline
\end{tabular}

$A U C_{0-t z}$ area under the plasma concentration-time curve of ethinylestradiol or levonorgestrel over the time interval from 0 to the last quantifiable data point, $C_{\max }$ maximum measured concentration of ethinylestradiol or levonorgestrel in plasma, $A U C_{0-\infty}$ area under the plasma concentration-time curve of ethinylestradiol or levonorgestrel over the time interval from 0 extrapolated to infinity, $T$ test, $R$ reference, gMean geometric mean, $g S E$ geometric standard error

aANOVA model was adjusted for the effects of "patient" and "treatment"

Table 4 Adverse events

\begin{tabular}{|c|c|c|c|c|c|}
\hline Adverse event & $\begin{array}{l}\text { Microgynon } \\
\text { alone }^{\mathrm{a}} \\
(n=17)\end{array}$ & $\begin{array}{l}\text { Nintedanib load- } \\
\text { ing phase }^{b} \\
(n=17)\end{array}$ & $\begin{array}{l}\text { Microgynon and } \\
\text { nintedanib }^{c} \\
(n=17)\end{array}$ & $\begin{array}{l}\text { Nintedanib alone after adminis- } \\
\text { tration of Microgynon }{ }^{\mathrm{d}} \\
(n=17)\end{array}$ & $\begin{array}{l}\text { Total } \\
(n=17)\end{array}$ \\
\hline Any adverse event & $3(17.6)$ & $11(64.7)$ & $4(23.5)$ & $2(11.8)$ & $12(70.6)$ \\
\hline Nausea & 0 & $6(35.3)$ & 0 & 0 & $6(35.3)$ \\
\hline Diarrhoea & 0 & $4(23.5)$ & $1(5.9)$ & 0 & $5(29.4)$ \\
\hline Vomiting & 0 & $5(29.4)$ & $1(5.9)$ & 0 & $5(29.4)$ \\
\hline Abdominal pain upper & 0 & $2(11.8)$ & $1(5.9)$ & 0 & $3(17.6)$ \\
\hline Headache & $2(11.8)$ & $1(5.9)$ & $1(5.9)$ & 0 & $3(17.6)$ \\
\hline Dizziness & $1(5.9)$ & $1(5.9)$ & 0 & 0 & $2(11.8)$ \\
\hline Abdominal pain & 0 & $1(5.9)$ & 0 & 0 & $1(5.9)$ \\
\hline Bronchitis & 0 & $1(5.9)$ & 0 & 0 & $1(5.9)$ \\
\hline Respiratory tract infection & 0 & $1(5.9)$ & 0 & 0 & $1(5.9)$ \\
\hline Rhinitis & 0 & $1(5.9)$ & 0 & 0 & $1(5.9)$ \\
\hline Musculoskeletal pain & 0 & $1(5.9)$ & 0 & 0 & $1(5.9)$ \\
\hline Pain in extremity & 0 & $1(5.9)$ & 0 & 0 & $1(5.9)$ \\
\hline Fatigue & $1(5.9)$ & 0 & 0 & 0 & $1(5.9)$ \\
\hline Malaise & $1(5.9)$ & 0 & 0 & 0 & $1(5.9)$ \\
\hline Drug-induced liver injury & 0 & 0 & $1(5.9)$ & 0 & $1(5.9)$ \\
\hline Increased aspartate transaminase & 0 & 0 & 0 & $1(5.9)$ & $1(5.9)$ \\
\hline Vaginal discharge & 0 & $1(5.9)$ & 0 & $1(5.9)$ & $1(5.9)$ \\
\hline
\end{tabular}

Data are $n(\%)$ of patients with $\geq 1$ such adverse event

${ }^{a}$ Adverse events reported from date of administration of Microgynon in Period 1 plus 3 days

${ }^{\mathrm{b}}$ Adverse events reported from first administration of nintedanib in Period 2 until the date of administration of Microgynon in Period 2

${ }^{\mathrm{c}}$ Adverse events reported from the date of administration of Microgynon in Period 2 plus 3 days

${ }^{\mathrm{d}}$ Adverse events reported from the date 3 days after the administration of Microgynon in Period 2 until the day after last contact

(drug-induced liver injury). The onset of the event was after 18 days of continuous intake of nintedanib and before combined administration of Microgynon and nintedanib. The patient was taking an antihistamine to treat rhinitis. This was discontinued the day after onset of liver injury, and the patient recovered after 10 days. No adverse events led to discontinuation of study medication. There were no clinically relevant changes in electrocardiogram recordings, vital signs, spirometry, or physical examinations. 


\section{Discussion}

Some patients with ILD who are prescribed nintedanib are of child-bearing age and are using hormonal contraception to prevent pregnancy. This is of importance, as nintedanib may cause foetal harm if administered to a pregnant woman [6]. The pharmacokinetic data from this study indicate that there is no relevant effect of nintedanib $150 \mathrm{mg}$ bid on exposure to ethinylestradiol and levonorgestrel in female patients with SSc-ILD. Thus, nintedanib would not be expected to reduce the effectiveness of contraceptives containing ethinylestradiol and levonorgestrel due to drug-drug interaction.

An increase in the peak exposure to ethinylestradiol was observed in the presence of nintedanib. This finding was not considered to be of clinical relevance. Although the AUC $0-\infty$ of levonorgestrel indicated a decrease in total exposure in the presence of nintedanib, this observation should be interpreted with caution, given that the majority of patients in both periods had extrapolated areas of $>30 \%$ due to pharmacokinetic sampling being limited to $48 \mathrm{~h}$. The AUC $0-t$, for which no extrapolation was necessary, is considered more reliable.

Ethinylestradiol is metabolised in the liver by hydroxylation, mediated by CYP3A4, while levonorgestrel is metabolised in the liver to sulfate and glucuronide conjugates [10]. Drugs that induce CYP3A4 can cause a decrease in exposure to oral contraceptives, which in turn may reduce their effectiveness [10-12]. Preclinical data have suggested that nintedanib has a low potential to induce CYP3A4 [7, 13]. Therefore, no relevant drug-drug interaction was expected when nintedanib was co-administered with oral contraceptives. This was confirmed in the present study.

The safety profiles of nintedanib and ethinylestradiol and levonorgestrel in this study were generally consistent with the known safety profiles of each drug $[6,10]$. There appeared to be no increase in adverse events when nintedanib was combined with ethinylestradiol and levonorgestrel compared with administration alone.

\section{Conclusions}

Pharmacokinetic data indicate that there is no relevant effect of nintedanib on plasma exposure to ethinylestradiol and levonorgestrel. Nintedanib is therefore not expected to reduce the effectiveness of contraceptives containing ethinylestradiol and levonorgestrel due to drug-drug interaction.

Acknowledgements We thank the patients and investigators who participated in this study. The authors meet criteria for authorship as recommended by the International Committee of Medical Journal Editors (ICMJE). The authors did not receive payment for development of this manuscript. Writing assistance was provided by Julie Fleming and Wendy Morris of FleishmanHillard, London, UK, which was contracted and funded by Boehringer Ingelheim. Boehringer Ingelheim was given the opportunity to review the manuscript for medical and scientific accuracy as well as intellectual property considerations.

\section{Declarations}

Funding This study was supported by Boehringer Ingelheim International $\mathrm{GmbH}(\mathrm{BI})$.

Conflict of interest MCV reports grants from BI, Ferrer and JanssenCilag; fees for serving as an advisor or review panel member for BI and Janssen-Cilag; and speaker fees from BI, Janssen-Cilag, Novartis, Roche. AG-D-C reports consultancy fees from BI and Janssen. MK reports grants from BI and Roche and consultancy fees from BI, Galapagos, Roche. MA, KM, SRM, SW and MG are employees of BI.

Data availability Researchers may request access to de-identified participant clinical study data with documentation describing the structure and content of the datasets. Upon approval, and governed by a Data Sharing Agreement, data would be shared in a secured data-access system for a period of 1 year, which may be extended upon request. Researchers should use the link https://trials.boehringer-ingelheim. $\mathrm{com} /$ to request access to study data.

Authors' contributions MA, KM, SRM, SW and MG were involved in the design of the study. MCV, AG-D-C and MK were involved in data acquisition. SRM and KM were involved in data analysis. All authors were involved in the interpretation of the data and in the writing and critical review of the manuscript and have approved the final version.

Ethics approval The clinical protocol was approved by an independent ethics committee or institutional review board at each participating centre.

Consent to participate All patients provided written informed consent before study entry.

Consent for publication Not applicable.

Open Access This article is licensed under a Creative Commons Attribution-NonCommercial 4.0 International License, which permits any non-commercial use, sharing, adaptation, distribution and reproduction in any medium or format, as long as you give appropriate credit to the original author(s) and the source, provide a link to the Creative Commons licence, and indicate if changes were made. The images or other third party material in this article are included in the article's Creative Commons licence, unless indicated otherwise in a credit line to the material. If material is not included in the article's Creative Commons licence and your intended use is not permitted by statutory regulation or exceeds the permitted use, you will need to obtain permission directly from the copyright holder. To view a copy of this licence, visit http://creativecommons.org/licenses/by-nc/4.0/.

\section{References}

1. Hilberg F, Tontsch-Grunt U, Baum A, et al. Triple angiokinase inhibitor nintedanib directly inhibits tumor cell growth and induces tumor shrinkage via blocking oncogenic receptor tyrosine kinases. J Pharmacol Exp Ther. 2018;364:494-503. 
2. Wollin L, Distler JHW, Redente EF, et al. Potential of nintedanib in treatment of progressive fibrosing interstitial lung diseases. Eur Respir J. 2019;54(3):1900161.

3. Richeldi L, du Bois RM, Raghu G, et al. Efficacy and safety of nintedanib in idiopathic pulmonary fibrosis. N Engl J Med. 2014;370:2071-82.

4. Distler O, Highland KB, Gahlemann M, et al. Nintedanib for systemic sclerosis-associated interstitial lung disease. N Engl J Med. 2019;380:2518-28.

5. Flaherty KR, Wells AU, Cottin V, et al. Nintedanib in progressive fibrosing interstitial lung diseases. N Engl J Med. 2019;381:1718-27.

6. Boehringer Ingelheim International GmbH. OFEV ${ }^{\circledR}$ (nintedanib) prescribing information. 2020. https://docs.boehringer-ingelheim. com/Prescribing\%20Information/PIs/Ofev/ofev.pdf. Accessed 30 Mar 2021.

7. Wind S, Schmid U, Freiwald M, et al. Clinical pharmacokinetics and pharmacodynamics of nintedanib. Clin Pharmacokinet. 2019;58:1131-47.

8. Stopfer P, Rathgen K, Bischoff D, et al. Pharmacokinetics and metabolism of BIBF 1120 after oral dosing to healthy male volunteers. Xenobiotica. 2011;41:297-311.
9. van den Hoogen F, Khanna D, Fransen J, et al. 2013 Classification criteria for systemic sclerosis: an American College of Rheumatology/European League Against Rheumatism collaborative initiative. Arthritis Rheum. 2013;65:2737-47.

10. Bayer plc. Microgynon ${ }^{\circledR}$ 30: summary of product characteristics. 2020.

11. Barditch-Crovo P, Trapnell CB, Ette E, et al. The effects of rifampin and rifabutin on the pharmacokinetics and pharmacodynamics of a combination oral contraceptive. Clin Pharmacol Ther. 1999;65:428-38.

12. Berry-Bibee EN, Kim MJ, Tepper NK, et al. Co-administration of St. John's wort and hormonal contraceptives: a systematic review. Contraception. 2016;94:668-77.

13. FDA Center for Drug Evaluation and Research. Nintedanib clinical pharmacology NDA review. 2014. http://www.accessdata.fda. gov/drugsatfda_docs/nda/2014/205832Orig1s000ClinPharmR. pdf. Accessed 30 Mar 2021.

\section{Authors and Affiliations}

\section{Madelon C. Vonk ${ }^{1}$ (D) Alfredo Guillén-Del-Castillo ${ }^{2} \cdot$ Michael Kreuter $^{3} \cdot$ Mandy Avis $^{4} \cdot$ Kristell Marzin $^{5}$. Salome R. Mack ${ }^{5}$. Sven Wind ${ }^{5} \cdot$ Martina Gahlemann $^{6}$}

Madelon C. Vonk

Madelon.Vonk@radboudumc.nl

1 Department of Rheumatology, Radboud University Medical Center, Nijmegen, The Netherlands

2 Unit of Systemic Autoimmune Diseases, Department of Internal Medicine, Hospital Universitari Vall d'Hebron, Barcelona, Spain

3 Center for Interstitial and Rare Lung Diseases, Pneumology and Respiratory Care Medicine, Thoraxklinik, University of Heidelberg, Member of the German Center for Lung Research, Heidelberg, Germany

4 Boehringer Ingelheim B.V., Alkmaar, The Netherlands

5 Boehringer Ingelheim Pharma GmbH \& Co. KG, Biberach an der Riss, Germany

6 Boehringer Ingelheim (Schweiz) $\mathrm{GmbH}$, Basel, Switzerland 